\title{
Characteristics of influential peers in the eyes of secondary school students: a mixed method study
}

\author{
Alice Y. Loke, Yim-wah Mak and Cynthia S.T. Wu \\ School of Nursing, The Hong Kong Polytechnic University, Hong Kong, SAR China
}

\begin{abstract}
Aim: It is the aim of this study to explore the characteristics of influential peers identified by schoolmates, and the mechanism by which they exert their influence on their peers. Background: Adolescent crowds are a salient influence on the health-risk behaviors of peers, contributing to adolescent substance use such as drinking alcohol, smoking cigarettes, and taking drugs. Methods: A mixed method study. Three schools granted us access to students and those who had been nominated as influential by their peers. The students were asked to nominate and indicated the characteristics of peers whom they considered influential in a quantitative study. Those peers whom they considered influential were invited to take part in focus group interviews. A total of six focus group interviews were conducted, comprised of two groups from each school, with an average of seven participants in each group. Findings: Students considered caring and friendliness $(91.0 \%)$, being a buddy $(88.5 \%)$, and entertaining/humor $(86.8 \%)$ as the top three characteristics of influential peers. The interviews revealed that the students believed that they are influential because of their cheerfulness and humor, considerateness, ability to communicate, popularity and sociability, sincerity and trustworthiness, and because they possess the characteristics of a leader. They also believed that their power to influence came about through their helpfulness, accommodation, and the closeness of their relationships. Their influence was manifested in both positive and negative ways on the academic pursuits and health-risk behaviors of their peers. In order to engage at-risk students in health promotion programs, it is important to identify their influential peers, and to understand how adolescent friends may help one another to resist behaviors that pose a risk to their health.
\end{abstract}

Key words: adolescence; influential peers; mixed method study; peer-to-peer relations; self-perception

Received 18 October 2016; revised 10 February 2017; accepted 16 April 2017;

first published online 11 May 2017

\section{Introduction}

Apart from their own homes, adolescents spend a large portion of their time in schools. School is a social context that offers adolescents opportunities to develop their personality and character by interacting with their school peers, teachers, and other school personnel (Farrell et al., 2006).

Correspondence to: Professor Alice Y. Loke, School of Nursing, The Hong Kong Polytechnic University, Hong Kong, SAR China. Email: alice.yuen.loke@polyu.edu.hk

(C) Cambridge University Press 2017
It is well accepted that peer crowd affiliation contributes most significantly to the development of the personal character of adolescents and to their adoption of various types of behavior. The similarities among peers in crowds can be attributed to the processes of 'peer selection' and 'peer socialization' (Brechwald and Prinstein, 2011). Peer selection refers to the tendency of adolescents to select and affiliate themselves with peers with similar characteristics when they find themselves among a crowd of people (Dijkstra et al., 2013). The similarities increase as 
socialization continues among peers in the same crowd and the mechanism of influence continues to be exerted. Adolescents tend to define and locate themselves by forming their values, beliefs, and behaviors within their peer groups (Brown et al., 2008).

In the school context, adolescents select and affiliate with peer groups to gain an identity and develop self-concept. Studies have found that adolescents searched and defined their individual identities and status among groups within their social context. They observed and reflected on their peers' perceptions of themselves to formulate their own concept of self (Brown et al., 2008; Doornwaard et al., 2012). A study has reported that positive interactions with school peers enhanced adolescents' conception of themselves (Ellis et al., 2009).

As social networks became established, the influence of adolescent crowds on the health-risk behaviors of peers became more salient. Studies have shown that peer influence is a substantial contributing factor in the use by adolescents of such substances as alcohol, cigarettes, and drugs (Ali and Dwyer, 2009; Simons-Morton and Farhat, 2010; Tucker et al., 2011). One study showed that the smoking rate among students increased by $5 \%$ if one-fourth of their close friends were smokers (Ali and Dwyer, 2009). Other studies also found that adolescents were significantly more likely to start drinking alcohol when more of their peers drank (Ali and Dwyer, 2010; Kiuru et al., 2010; Trucco et al., 2011). The incidence of marijuana use among adolescents was also significantly higher when they have a close relationship with deviant peers who take drugs (Tucker et al., 2013). A recent study in Hong Kong also reported on the influence of students on their peers in terms of negative impacts on health-risk behaviors such as smoking and drinking (Loke et al., 2016).

Peer influences can be positive as well. Studies have shown that positive peer affiliation is constructive to the development of adolescents, by promoting social behavior and positive values and beliefs. A study showed that African American adolescents had better academic achievement and social adjustment when they had positive experiences in getting along with their peers (Hamm et al., 2013). Other studies have also suggested that peer influence can promote the development of healthy behavior in adolescents. For example, school peers with healthy eating behavior would encourage other students to engage in such behavior or in other healthy behaviors (Pearson et al., 2011; Bruening et al., 2012; Rew et al., 2013). Adolescents would adapt prosocial behavior from their close friends who exhibit such behavior during the process of peer socialization (Barry and Wentzel, 2006; Peters et al., 2010).

Although peer influence has long been discussed and studied, no previous study has explored the characteristics of such influential peers and the mechanism of such influence are not well understood. It is the aim of this study to explore the characteristics of influential peers and the mechanism by which those peers exert their influence. A better understanding of the characteristics and mechanisms of peer influence can provide the necessary information to develop peer-led programs to reduce adolescent participation in behaviors that put their health at risk, or to promote positive influences.

\section{Methods}

\section{Study objectives}

This is a study to identify the characteristics of influential peers among secondary students in Hong Kong. The specific objectives are to identify (1) the characteristics on influential peers reported by their schoolmates who were deemed to be influential across the wider student body, (2) the self-reported characteristics of the students who have been nominated as influential, the perceptions of influential students of the process/mechanism of their influence, and how such influence affects the positive development of peers or their uptake of behaviors that put their health at risk.

\section{Study design}

This is a mixed method study in examining the characteristics of influential students in secondary schools.

\section{Participants}

The school principals of six schools granted us access for the study. The schools were situated in the Kowloon and New Territories districts of Hong Kong where mostly middle-socioeconomic class 
families lived. Secondary students studying in Year 3 were the target population. These students were chosen because they are age 13-15 years old, and have been studying together for at least two years.

\section{Quantitative study}

Secondary students studying in Year 3 in the six schools were asked to nominate by anonymous ballot up to three peers whom they considered influential, and to indicate the characteristics of these peers personally influential to them or deemed to be influential across the wider student body.

\section{Qualitative study}

The school principals of the six schools were sent a letter requesting the arrangement of the group interviews, together with a list of the nominated students. Of the six schools that offered us access for the first stage of the study, only three agreed to allow us to conduct interviews of the nominated influential peers. Only the students who were nominated by at least three of their school peers as influential from the three schools were invited to participate in a focus group interview, to explore their perception of their characteristics that made them influential.

\section{Research personnel and interviewers}

Eight university nursing students were recruited to distribute and collect the questionnaires in class, and conduct the group interviews a few months later after a list of the nominated students was compiled. All of the nursing students had taken the subject 'Child Psychology,' and had some interviewing skills from taking the subject 'Mental Health Assessment.' Nevertheless, they were provided training on interview skills using the semi-structured questions developed by the research team. University students were recruited to collect the questionnaires and conduct these group interviews because they were not that much older than the secondary school students that they would be interviewing, and might therefore have a better understanding of these students and be more readily accepted by them.

\section{Instruments}

The questionnaire for the quantitative study contains 14 items that were combined and modified from three established instruments from literatures to identify the characteristics of influential students. These instruments included the peer-valued characteristics of perceived popularity (Vaillancourt and Hymel, 2006); sociometric questionnaire to assess peer-perceived admiration, academic disengagement, academic application, and physical attractiveness (Becker and Luthar, 2007); behavioral assessment of aggressiveness, snobbishness, submissiveness, and pro-sociality (Gorman et al., 2002). Students were asked to indicate whether they agree or disagree of the characteristics of those influential peers. The $\alpha$ reliability coefficients for the modified instruments ranged from 0.76 to 0.93 .

The interviews were conducted according to an interview guide that was designed to explore the self-reported characteristics of the influential students. Questions such as the following were included: 'Do you consider yourself influential?'; 'What qualities do you possess that make you influential?'; 'What kind of influence do you have on your peers and to what degree?'; 'Please give examples to illustrate how you have impacted your peers'; 'Do you have any influence on your peers with regard to health-related behavior?'; and 'How do you think you influence your peers on health-related behavior?' The semi-structured interviews lasted for not more than $90 \mathrm{~min}$ and were audio-taped. All of the interviews were conducted in Cantonese (the dialect that the students feel most comfortable speaking).

\section{Data collection}

The research team and the school principals agreed on the dates of the questionnaire distribution and interviews, which were held at the beginning and end of the academic year, respectively.

The anonymous questionnaires were distributed and collected by the nursing students in the classrooms without the presence of teachers. Students were asked to nominate by anonymous ballot up to three peers whom they considered influential and to indicate the characteristics of these peers personally influential to them or deemed to be influential across the wider student body.

The group interviews took place in a quiet room at the school on a day when classes were not being held, to avoid interference from other students and from school activities. A total of six focus group 
interviews were conducted, comprised of two groups from each of the three schools, with each group consisting of an average seven participants. Refreshments were provided to develop an atmosphere of relaxation for the free expression of views. The interview sessions started with a self-introduction by the trained interviewers. The secondary school students were then asked to introduce themselves to 'break the ice.' One member of the research team was present to monitor the interview, but did not get directly involved in the interview. The member of the research team who was responsible for the interviews is a certified counselor, and was prepared to take non-verbal hints from the students to either provide support or leave the room.

\section{Ethical considerations}

Ethical approval was obtained from the Ethics Committee of the Hong Kong Polytechnic University (HSEARS No. 20120624001) prior to the commencement of the study. Permission from the secondary school principals was obtained. An information sheet explaining the aims of the study and a refusal form were sent to the parents through the school principals. The students who returned the questionnaire in class were considered given an implied consent. All of the nominated students who showed up at the interview session were given a full explanation of the aims of the study and were informed that they could withdraw from the study at any point during the interview. Those whose parents did not return a refusal form and showed up at the interviews were considered have given implied consent. They were also assured of confidentiality and anonymity.

\section{Data analysis}

All of the data collected from the quantitative study were entered and analyzed using the Statistical Package for Social Sciences version 17.0 for Windows. Simple descriptive statistics with frequencies and percentages were tabulated.

The verbatim transcripts were transcribed into written Chinese within two weeks after the interviews. Inductive thematic analysis was used to analyze the transcripts. The inductive thematic approach to analyzing qualitative data was used to derive key themes from the data without any pre-existing coding frame (Braun and Clarke, 2006). The process of analysis consisted of first having each of the members of the research team separately read and re-read the interview transcripts and individually code the data line by line. They were instructed to follow the steps to systematically code the common and relevant data under special aspects of the accounts of the secondary school students and the description of the specific characteristics of influential peers. Codes were to be combined into potential themes according to their similarities and differences and agreed upon by the research team members. All of the relevant data were classified under specific themes.

A meeting was held with the members of the research team and the university student interviewers to discuss the themes that had been identified. Sets of analyzed themes were reviewed and refined continuously until a consensus was reached. Finally, significant themes were established that provided a picture of the key elements of the influential students' perceptions of their characteristics, the mechanism of their influence, and the impacts on their peers. Statements or keywords with the same meaning given by the students during the interviews were finalized and merged under the same themes (in Chinese). It is until the step of report writing, that the themes were translated and presented in English.

\section{Results}

In the months of September and October 2013, a total of 840 out of the 882 questionnaires distributed to all the Year 3 students of the six secondary schools were completed and returned, for a response rate of $95.2 \%$. Of the total of 840 Year 3 students in the study, 438 (52.1\%) were male and $402(47.9 \%)$ were female. The students were $12-15$ years old $(n=799,95.2 \%)$, and 41 $(4.9 \%)$ students were 16 years old or above.

\section{Characteristics deemed to be influential to students or across the wider student body}

Table 1 shows the frequencies and percentages of students who considered the characteristics deemed to be influential personally to students or across the wider student body. The three characteristics that were rated by most students as influential were with caring and friendliness top 
Table 1 Characteristics of influential students as reported by Year 3 students $(n=840)$

\begin{tabular}{ll}
\hline Characteristics of the influential students & Agree $[n(\%)]$ \\
\hline Caring and friendliness & $765(91.7)$ \\
Brotherhood/sisterhood (buddy) & $744(88.6)$ \\
Entertaining (humor) & $730(86.9)$ \\
Generosity & $725(85.4)$ \\
Sincerity and trustworthiness & $699(83.2)$ \\
Sociability & $693(82.5)$ \\
Motivated in academic performance & $648(77.1)$ \\
Assertiveness & $648(77.1)$ \\
Talented & $635(75.6)$ \\
Peer-perceived admiration & $599(71.3)$ \\
Good academic performance & $555(66.1)$ \\
Physical attractiveness & $394(46.9)$ \\
Academic disengagement (-) & $224(26.7)$ \\
Snobbishness (-) & $172(20.5)$ \\
\hline
\end{tabular}

the list $(n=765,91.7 \%)$, being a buddy rated second ( $n=744,88.6 \%)$, and followed by entertaining $(n=730,86.9 \%)$.

Those who are motivated in academic performance $(n=648,77.1 \%)$ instead of those with good academic performance $(n=555,66.1 \%)$ were rated by most students as influential. The qualities considered influential were generosity ( $n=725,85.4 \%)$, and sincerity and trustworthiness $(n=699,83.2 \%)$.

The three characteristics that were rated as least influential were physical attractiveness $(n=394$, $46.9 \%)$, academic disengagement $(n=224,26.7 \%)$, and snobbishness $(n=172,20.5 \%)$.

\section{Nominated influential peers' account of the characteristics that made them influential}

Three main themes emerged from analyzing the transcripts of the interviews: (1) individual personality; (2) established relationships as a mechanism of influence; and (3) influence on the behaviors of peers.

\section{Individual personality}

The influential peers considered that their individual personality contributed to their potential to exert an influence on peers and popularity. The influential peers perceived that they had been nominated by their peers as influential because of such personal qualities as: cheerfulness, humor, considerateness; ability to communicate, sincerity and trustworthiness, leadership abilities, popularity, and sociability.

Cheerfulness and humor: The peers identified cheerfulness and humor as the personality traits that made them influential. They considered that being cheerful and humorous brought joy to their peers and caused them to have more friends than other people. The influential peers thought that this kind of personality creates an uninhibited atmosphere for sharing and facing challenges.

When I meet peers in school, I greet them cheerfully. After several times, we became friends and started to share our thoughts.

(WA38)

Being humorous, I instill a relaxed atmosphere so that peers can open up and share their feelings.

Considerateness: The influential students believed that being considerate of others made them popular with their peers. Being considerate, sensitive, and caring of other people's feelings gave them a friendly image. The influential peers believed that this made their friends feel warm, safe, and respected.

I am sensitive to the feelings of my friends and make they feel that their needs are important.

(WA 473)

I think my friends nominated me as influential because I can tell whether my friends are upset by just looking at their facial expressions. I will express my concerns and comfort them.

(WA81)

I am considerate of my teammates. I always send reminders through the Internet or electronic means to team members the day before our team's activities and thank them for their contributions after the activities are over.

(PB538)

Communicative (non-judgmental listening, skills of persuasion): Being communicative was one of the personal traits that young people

Primary Health Care Research \& Development 2017; 18: 429-440 
considered a reason why they had been nominated as influential. They can initiate a dialogue so that their peers can voice their feelings or thoughts. The influential peers are also able to communicate in a non-judgmental and tactful manner to establish an appropriate atmosphere for sharing.

I like to listen to other people's feelings. My friends do share with me their feelings of unhappiness or tell me when they are upset. I listen to what they say. Sometimes they just need someone to listen without giving them opinions or suggestions. Being a good listener may be the reason why I have been nominated as influential.

(WA39)

When my friends are upset, I will sit down to listen to them, and be careful to not pass judgment.

(TB114)

If my friends have made some mistakes, I will tactfully point out the problem. I will discuss different perspectives with them, let them see their own strengths and weaknesses, and not directly give suggestions or criticism.

(PA62)

Sincerity and trustworthiness: The students who had been identified as influential considered that their sincerity and trustworthiness had given them influence over their peers. Their peers felt comfortable with their relationship and with being involved in projects/activities with them. Their peers were willing to accept their suggestions and to rely on them because they are sincere and trustworthy.

My friends feel at ease when they work with me in our projects; I am reliable and trustworthy and am someone they can depend on.

(WA83)

My friends think I am friendly, sincere, and reliable. They usually consider my opinions when making a decision. They trust my opinion, and that I am there to help them with my heart, so they usually follow my suggestions.
My peers see me as being friendly, responsible, and reliable. So they like to have a close relationship with me and to 'learn' from me.

(PB157)

Leadership: The influential students considered that their leadership characteristics had an influence on their peer group. Leadership can increase the sense of certainty within groups and help to maintain a sense of fellowship among the groups. They stated that leadership includes showing initiative, having good organizational skills, and offering constructive suggestions.

I usually take the lead in actions and give them explanations of my ideas, and my friends like to follow me in my actions.

(WB119)

I can take the lead, and organize and assign tasks among my peer group. I also offer different ways to solve the problems that we encounter in the process. Many times, I was able to persuade my peers to work on things differently.

I was nominated to take a leadership course offered by Hong Kong Gifted Education. I think that I was nominated as influential because I am the only student in the junior year (Form 3) to be a committee member in the student association. I assisted in organizing numerous activities in the school.

(PB20)

Sociability: The influential students reported that they are popular among their peers and sociable in groups.

The students believed they are considered influential probably because of their popularity and sociability. They reported that they have a big social network, and are often welcomed by friends in social gatherings.

I am popular in inter-secondary school activities. I even draw many of my friends to participate in these activities that broaden their horizons.

(PB76) 
I am very sociable and can make friends easily. After several social gatherings, I already establish friendships and trust that people will seek my advice for their problems or for decisions that they need to make.

\section{Established relationships as a mechanism} of influence

In the interviews, the influential peers expressed the view that an established relationship is a prerequisite in the process of exerting influence. It is through helpfulness, accommodation, and close relationships that influence on peers is generally exerted.

Helpfulness: The influential students identified helpfulness as a key factor in developing influential relationships. They are willing to give assistance whenever their peers are in need; this enhances the relationship and creates an opportunity for them to influence their peers.

Whenever we have difficulties in our school assignments, we will work together and help each other in solving problems.

(TA105)

My helpfulness makes me a welcomed person among my peers. I even help those that I do not really have a close relationship with. My friends were happy to be around me, and in turn help each other. I develop friendships with others by being helpful in school.

(PB486)

I helped my friends by studying together for our examinations. One of my friends once told me that I caused him to reflect on his own selfishness and now takes me as his role model.

Accommodation: The influential peers deemed that being accommodative was a characteristic of theirs that led them to develop influence over others. They understand that each individual has a unique personality and different talents, and they understand that it is important to accept individual differences among their peers to make friends and have influence over them.

I am easygoing and accommodative. I don't mind if my friends voice their different opinions or tease me. I also accept and respect the different characters of my friends.

(TB178)

As a leader among my peers, I need to be articulate in expressing my viewpoints, but at the same time understand the differences, strengths, and abilities of my peers. I keep calm and refrain from rudeness and arguments. I manage difficult situations with tact and give some suggestions for improvement instead of pointing at others' weaknesses.

(PA218)

Closeness: The influential students believed that close relationships established though helping and accommodative relationships are the mechanism of influence. Particularly when peers have similar interests and activities, it is through closeness that peers learn to accept each other and influence others and vice versa.

Close friendships can be developed while sharing common interests. My friends who share the same interests follow my decision to join extra-curriculum activities together. Our relationship has become closer because we do things together, and my friends like to follow me in whatever I do.

(WA244)

Being friendly and playful, I have established close relationships with many of my peers. We have shared many of our troubles and deep feelings, and now my friends always come to me for my suggestions and opinions. I don't think this would happen if we did not have a close relationship.

(PB196)

\section{Influence on peers}

The interviews with the influential students indicated that through the process of socialization, they exerted a positive influence on their peers, motiving them in academic pursuits, and in refusing/ avoiding engagement in risky health behaviors. 
However, there were also some reports of negative influences on peers with regard to the acceptance and uptake of health-risk behaviors.

Motivation in academic pursuits: The influential students maintained that they influenced their peers to put more effort into their academic studies. They asserted that by establishing a collaborative learning atmosphere they had a positive effect on their peers, as they spent time studying together and helping each other to make better grades.

I am focused and determined to do well in school. I keep motivating my peers to improve their academic performance and constantly reminded them of its importance. Many of them now study with me.

(WA61)

I am good at mathematics so my peers always ask me to work with them in solving mathematics problems, and we have started to study together in other subjects as well.

(WB101)

I am outstanding in my academic performance. My peers always enjoy studying with me, and I can explain what I understand to them and help them to understand the subject matter.

(WB107)

I would invite my classmate's friends to join me in a tutorial class, inter-school quiz, and inter-school debate competition. Many of them listened to my advice and have improved in their academic performances.

(PB96)

Positive impacts on refusal or avoidance of health-risk behaviors: The influential students asserted that they had a positive influence on their peers' refusal to take part in health-risk behaviors. Not only did they try to set themselves up as role models to their peers by refusing offers of cigarettes, alcohol, and drugs; they also persuaded their peers not to use these substances, tried to offer help, and suggested that their peers seek help. The following excerpts are a few examples of their positive influence on their peers' smoking, drinking, and drug use.
On smoking:

My friend intended to smoke cigarettes in front of me, I suggested that he eat chocolates or something else instead and not take up a cigarette. I don't let my friend smoke when I am around.

(TA167)

I have always persistently refused invitations to smoke, and dissuade others from smoking.

(TA185)

I have suggested to my friend that he quit, and I help him to stay away from friends who smoke.

(TA238)

My friend was upset, and wanted to smoke a cigarette, I tried to calm her down and offer her emotional support. I told her that she does not need more trouble.

(WA171)

\section{On drinking:}

When my friends were going to drink beer when we were having hot pot, I suggested that they drink coke instead of beer.

(TB419)

When my peers drink, I try to find out the reason for this and try to dissuade them from drinking.

(WA416)

\section{On drug use:}

I refused to try a drug that was once offered to me because I know that it would harm my body. I also stopped my friend from continuing to take drugs, and advised him to stop.

(TB518)

When someone invited us to take drugs, I asked my peers to leave with me in order to get out of it.

(TB571)

If my friend use drug, I will dissuade him not to.

(WA207)

Negative impacts on health-risk behaviors: However, as expected, there were negative 
influences among peers in their health-risk behaviors. In peer groups, some accept drinking alcohol and smoking as social behaviors in gatherings. Some consider smoking and drinking as entertainment to kill time, and using drugs as a way to reduce stress/pressure in life. The influential students have also been negative role models in their peer groups with regard to smoking, drinking, and using drugs.

\section{On smoking:}

If my close friend offers me a cigarette, I will accept it because I value our friendship. But I only accept it as a gift and do not light it up.

(WA478)

I do not resist smoking cigarettes and accept it as a form of social behavior. My parents smoke too.

(WA89)

I don't mind my friends smoking around me because they feel bored. They just use cigarettes to kill time and to ease their stress.

(TB197)

\section{On drinking:}

I accept the social drinking of alcohol. I think that a small amount of alcohol is actually beneficial for health. But I do not know exactly how small the amount should be.

(WA340)

In our gatherings, my friends will suddenly go to the convenience store to buy several cans of beer. I try to dissuade them from drinking. Unfortunately, I have not been successful. They continue to drink, so I have dropped the topic. I guess social drinking is acceptable.

(WA284)

I accept social drinking for celebrations or gatherings. I only do not accept getting drunk.

(TB362)

\section{On drug use:}

When a new friend used drugs and offered me his drugs, I refused the offer and stayed away from that friend. However, I have continued my friendship with a close friend who I suspect uses drugs, and have neglected this aspect of behavior of his. We are good friends; I do not want to lose this friend.

(WA142)

I think using drugs once in a while is not a big deal. Young people use drugs to reduce the stress/pressure of life. Drugs can help them to relax a bit and forget the frustrations in life.

(WA188)

Overall, the interviews revealed that young people do have the ability in their peer groups to sway their friends positively as well as negatively on behaviors that put their health at risk.

\section{Discussion}

In this study, the perception of the characteristics deemed to be influential to students or across the wider student body were very similar to that reported by the nominated influential peers in the interviews. With the interviews revealed more indepth account of the characteristics and the mechanisms of their influence, and how such influence affects the health behaviors of their peers.

The study revealed that influential peers believed that they are influential because of their cheerfulness and humor, their consideration, communicativeness, popularity and sociability, sincerity and trustworthiness, and leadership abilities. They also believed that it was through their helpfulness, accommodativeness, and close relationships that they exerted influence over their peers. The closeness of their relationships appears to be the mechanism through which their influential relationships were exercised. Their influences were manifested in both positive and negative ways on the academic pursuits and health-risk behaviors of their peers. It is worth to note the characteristics of influential peers identified in this study among Chinese adolescents are similar to those reported in the western countries, and supported by the findings in literature (Gorman et al., 2002; Becker and Luthar, 2007; Peters et al., 2010).

Of these characteristics, being popular and sociable appeared to be the key factors in the ability of the influential students to attract more

Primary Health Care Research \& Development 2017; 18: 429-440 
friends than their peers. Popularity increases the attraction of a person, particularly to adolescents with low status in the peer selection process. These adolescents gain friendships in the peer selection process (Brechwald and Prinstein, 2011).

In turn, the popularity of influential peers enhances their power to influence their members. Adolescents follow the behavior of their popular peers to gain a favorable self-identity in the social context (Brechwald and Prinstein, 2011). Here, the process of social reinforcement and role modeling enhances the adaptation of the behavior of popular peers (Bandura, 1986).

Apart from popularity, the study also showed that in the beginning adolescents establish friendships with their peers based on their similarity. Common interests and activities contribute to the formation of mutual friendships among groups (Green et al., 2013). As the process of socialization continues, the behavioral similarity within the groups will increase (Popp et al., 2008). Therefore, similarity is not only the pre-existing feature in peer selection but also the product of peer socialization.

An established relationship acts as a mechanism of influence since it alters the susceptibility of peers to a person's actions. The power to influence one's peers increases to the point where the peers are vulnerable to adopting the behavior of the influential individuals. The positive quality of a friendship enhanced the influence over peers in the areas of antisocial behavior (Piehler and Dishion, 2007; Prinstein et al., 2011), substance use (Urberg et al., 2003), and prosocial behavior (Barry and Wentzel, 2006).

\section{Limitations}

This study was conducted in only six and three schools, respectively, in quantitative and qualitative parts of the study, where the principals allowed access. In particular, those schools that refused to allow us access may have some concerns over what their students might reveal in the interviews. It was noted that the students did not reveal their potential influence in the adoption of healthy lifestyles, or actually admitted that they had adopted risky behaviors such as smoking, drinking, take drugs, bullying, etc. These peers may have been reporting socially desirable responses in the interviews. Thus, the results may not be generalizable to school-age children in other schools.

\section{Conclusion}

This study examined the characteristics of influential adolescents perceived by peers and reported by those nominated as influential by their peers. The fields of peer influence could benefit from more studies that led light on the nuances of the characteristics of influential peers.

The results of this study show that peers may protect one another from activities that put their health at risk (Maxwell, 2002; Wu et al., 2007). In theory, peers are expected to be able to reach out to those who are 'at risk' and reinforce healthrelated messages (Turner and Shepherd, 1999). Health messages delivered by peer friends may be more readily accepted than those from teachers or parents. For health promotion programs among peers, the inclusion of influential peers could have positive outcomes, as they might be able to increase the involvement of at-risk students.

However, although some peer-led health promotion efforts have shown promising results, the evidence of the effectiveness of this approach is inconclusive (Harden et al., 2001). This is possibly due to the fact that the majority of school-based, peer-led education projects identified peers by selfselection, teacher selection, or a combination of both methods. These selection methods are sub-optimal, as the students that were identified through these processes were not often considered influential by their peers (Valente and Pumpuang, 2007). Teachers are likely to nominate those who are academic achievers, well-behaved, or well-liked by teachers, but these students may not be welcomed by their classmates. They may be good students, but may not very effective at influencing peers in their social circle (Valente and Pumpuang, 2007).

In order to engage at-risk students in health promotion programs, it is important to identify their influential peers, and to understand how adolescent friends may help one another to resist behaviors that put their health at risk.

\section{Acknowledgment}

The project team would like to thank Ms. Jennifer Chan, Ms. Alice Cheung, and Ms. YK Leung, who served as project assistants at different time of this project. Many thanks to the students who assisted in the data collection process and served as 
facilitators for the interviews in the participating secondary schools.

\section{Financial Support}

The authors would like to acknowledge the financial support received from the Health and Health Services Research Fund of Hong Kong No. 10111871, which made this project possible.

\section{Conflicts of Interest}

None.

\section{References}

Ali, M.M. and Dwyer, D.S. 2009: Estimating peer effects in adolescent smoking behavior: a longitudinal analysis. Journal of Adolescent Health 45, 402-8.

Ali, M.M. and Dwyer, D.S. 2010: Social network effects in alcohol consumption among adolescents. Addictive Behaviors 35, 337-42.

Bandura, A. 1986. Social foundations of thought and action: a social cognitive theory. Englewood Cliffs, NJ: Prentice-Hall.

Barry, C.M. and Wentzel, K.R. 2006: Friend influence on prosocial behavior: the role of motivational factors and friendship characteristics. Developmental Psychology 42, 153-63.

Becker, B. and Luthar, S. 2007: Peer-perceived admiration and social preference: contextual correlates of positive peer regard among suburban and urban adolescents. Journal of Research on Adolescence 17, 117-44.

Braun, V. and Clarke, V. 2006: Using thematic analysis in psychology. Qualitative Research in Psychology 3, 77-101.

Brechwald, W.A. and Prinstein, M.J. 2011: Beyond homophily: a decade of advances in understanding peer influence processes. Journal of Research on Adolescence 21, 166-79.

Brown, B.B., Von Bank, H. and Steinberg, L. 2008: Smoke in the looking glass: effects of discordance between self-and peer rated crowd affiliation on adolescent anxiety, depression and self-feelings. Journal of Youth and Adolescence 37, 1163-177.

Bruening, M., Eisenberg, M., MacLehose, R., Nanney, M.S., Story, M. and Neumark-Sztainer, D. 2012: Relationship between adolescents' and their friends' eating behaviors: breakfast, fruit, vegetable, whole-grain, and dairy intake. Journal of the Academy of Nutrition and Dietetics 112, 1608-1613.

Dijkstra, J.K., Cillessen, A.H. and Borch, C. 2013: Popularity and adolescent friendship networks: selection and influence dynamics. Developmental Psychology 49, 1242-252.

Doornwaard, S.M., Branje, S., Meeus, W.H. and ter Bogt, T.F. 2012: Development of adolescents' peer crowd identification in relation to changes in problem behaviors. Developmental Psychology 48, 1366-380.
Ellis, L.A., Marsh, H.W. and Craven, R.G. 2009: Addressing the challenges faced by early adolescents: a mixed-method evaluation of the benefits of peer support. American Journal of Community Psychology 44, 54-75.

Farrell, A.D., Sullivan, T.N., Kliewer, W., Allison, K.W, Erwin, E.H., Meyer, A.L. and Esposito, L. 2006: Peer and school problems in the lives of urban adolescents: frequency, difficulty, and relation to adjustment. Journal of School Psychology 44, 169-90.

Gorman, A., Kim, J. and Schimmelbusch, A. 2002: The attributes adolescents associate with peer popularity and teacher preference. Journal of School Psychology 40, 143-65.

Green, H.D. Jr, Horta, M., de la Haye, K., Tucker, J.S., Kennedy, D.R. and Pollard, M. 2013: Peer influence and selection processes in adolescent smoking behavior: a comparative study. Nicotine \& Tobacco Research 15, $534-41$.

Hamm, J.V., Lambert, K., Agger, C.A. and Farmer, T.W. 2013: Promotive peer contexts of academic and social adjustment among rural African American early adolescent boys. American Journal of Orthopsychiatry 83, 278-88.

Harden, A., Oakley, A. and Oliver, S. 2001: Peer-delivered health promotion for young people: a systematic review of different study designs. Health Education Journal 60, 339-53.

Kiuru, N., Burk, W.J., Laursen, B., Salmela-Aro, K. and Nurmi, J. 2010: Pressure to drink but not to smoke: disentangling selection and socialization in adolescent peer networks and peer groups. Journal of Adolescence 33, 801-12.

Loke, A.Y., Mak, Y.W. and Wu, C.S.T. 2016: The association of peer pressure and peer affiliation with the health risk behaviors of secondary school students in Hong Kong. Public Health 137, 113-23.

Maxwell, K.A. 2002: Friends: the role of peer influence across adolescent risk behaviors. Journal of Youth and Adolescence $31,267-77$.

Pearson, N., Ball, K. and Crawford, D. 2011: Predictors of changes in adolescents' consumption of fruits, vegetables and energy-dense snacks. British Journal of Nutrition 105, 795-803.

Peters, E., Cillessen, A.H., Riksen-Walraven, J.M. and Haselager, G.J. 2010: Best friends' preference and popularity: associations with aggression and prosocial behavior. International Journal of Behavioral Development 34, 398-405.

Piehler, T.F. and Dishion, T.J. 2007: Interpersonal dynamics within adolescent friendships: dyadic mutuality, deviant talk, and patterns of antisocial behavior. Child Development 78, 1611-624.

Popp, D., Laursen, B., Kerr, M., Stattin, H. and Burk, W.K. 2008: Modeling homophily over time with an actor-partner interdependence model. Developmental Psychology 44, 1028-39.

Prinstein, M.J., Brechwald, W.A. and Cohen, G.L. 2011: Susceptibility to peer influence: using a performance-based measure to identify adolescent males at heightened risk for deviant peer socialization. Developmental Psychology 47, 1167-172. 
Rew, L., Arheart, K.L., Thompson, S. and Johnson, K. 2013: Predictors of adolescents' health-promoting behaviors guided by primary socialization theory. Journal of Specialists in Pediatric Nursing 18, 277-88.

Simons-Morton, B.G. and Farhat, T. 2010: Recent findings on peer group influences on adolescent smoking. The Journal of Primary Prevention 31, 191-208.

Trucco, E.M., Colder, C.R. and Wieczorek, W.F. 2011: Vulnerability to peer influence: a moderated mediation study of early adolescent alcohol use initiation. Addictive Behaviors 36, 729-36.

Tucker, J.S., De La Haye, K., Kennedy, D.P., Green, H.D. Jr and Pollard, M.S. 2013: Peer influence on marijuana use in different types of friendships. Journal of Adolescent Health $54,67-73$.

Tucker, J.S., Green, H.D. Jr, Zhou, A.J., Miles, J.N., Shih, R.A. and D'Amico, E.J. 2011: Substance use among middle school students: associations with self-rated and peernominated popularity. Journal of Adolescence 34, 513-19.
Turner, G. and Shepherd, J. 1999: A method in search of a theory: peer education and health promotion. Health Education Research 14, 235-47.

Urberg, K.A., Luo, Q., Pilgrim, C. and Degirmencioglu, S.M. 2003: A two-stage model of peer influence in adolescent substance use: individual and relationship-specific differences in susceptibility to influence. Addictive Behaviors 28, $1243-256$.

Vaillancourt, T. and Hymel, S. 2006: Aggression and social status: the moderating roles of sex and peer-valued characteristics. Aggressive Behavior 32, 396-408.

Valente, T.W. and Pumpuang, P. 2007: Identifying opinion leaders to promote behavior change. Health Education \& Behavior 34, 881-96.

Wu, W., Chang, H., Yen, L. and Lee, T.S. 2007: Changes in health risk behaviors of elementary school students in northern Taiwan from 2001 to 2003: results from the child and adolescent behaviors in long-term evolution study. BMC Public Health 7, 323. 